\title{
Rectal Cream Dosage Form
}

National Cancer Institute

\section{Source}

National Cancer Institute. Rectal Cream Dosage Form. NCI Thesaurus. Code C69045.

A cream intended for administration in or around the rectum. 